
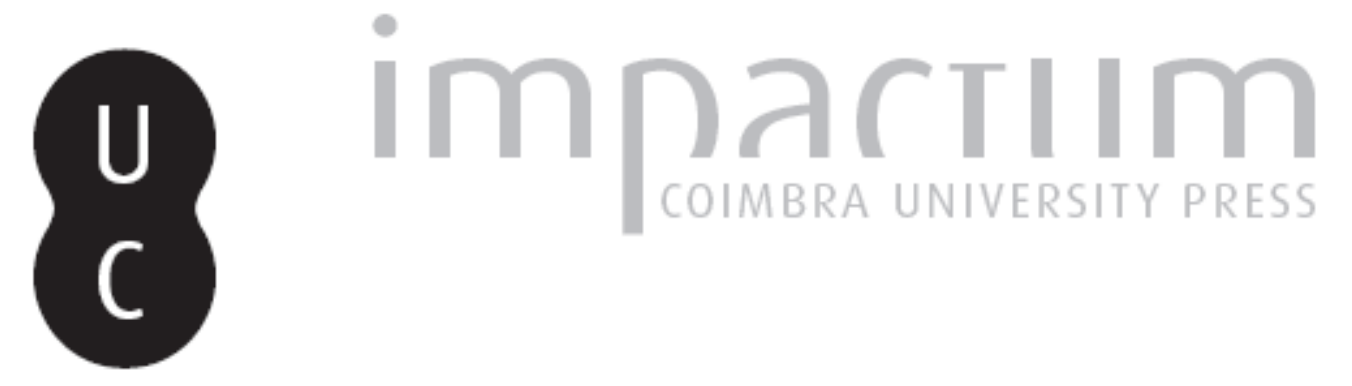

\title{
2.. Reflexão sobre o perfil do curso e o papel da Teoria da Arquitectura
}

Autor(es): $\quad$ Cabrita, António Reis

Publicado por: Editorial do Departamento de Arquitectura

URL persistente:

URI:http://hdl.handle.net/10316.2/37436

DOI:

DOI:http://dx.doi.org/10.14195/0874-6168_2_5

Accessed : $\quad$ 26-Apr-2023 15:37:12

A navegação consulta e descarregamento dos títulos inseridos nas Bibliotecas Digitais UC Digitalis, UC Pombalina e UC Impactum, pressupõem a aceitação plena e sem reservas dos Termos e Condições de Uso destas Bibliotecas Digitais, disponíveis em https://digitalis.uc.pt/pt-pt/termos.

Conforme exposto nos referidos Termos e Condições de Uso, o descarregamento de títulos de acesso restrito requer uma licença válida de autorização devendo o utilizador aceder ao(s) documento(s) a partir de um endereço de IP da instituição detentora da supramencionada licença.

Ao utilizador é apenas permitido o descarregamento para uso pessoal, pelo que o emprego do(s) título(s) descarregado(s) para outro fim, designadamente comercial, carece de autorização do respetivo autor ou editor da obra.

Na medida em que todas as obras da UC Digitalis se encontram protegidas pelo Código do Direito de Autor e Direitos Conexos e demais legislação aplicável, toda a cópia, parcial ou total, deste documento, nos casos em que é legalmente admitida, deverá conter ou fazer-se acompanhar por este aviso.

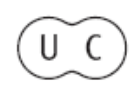




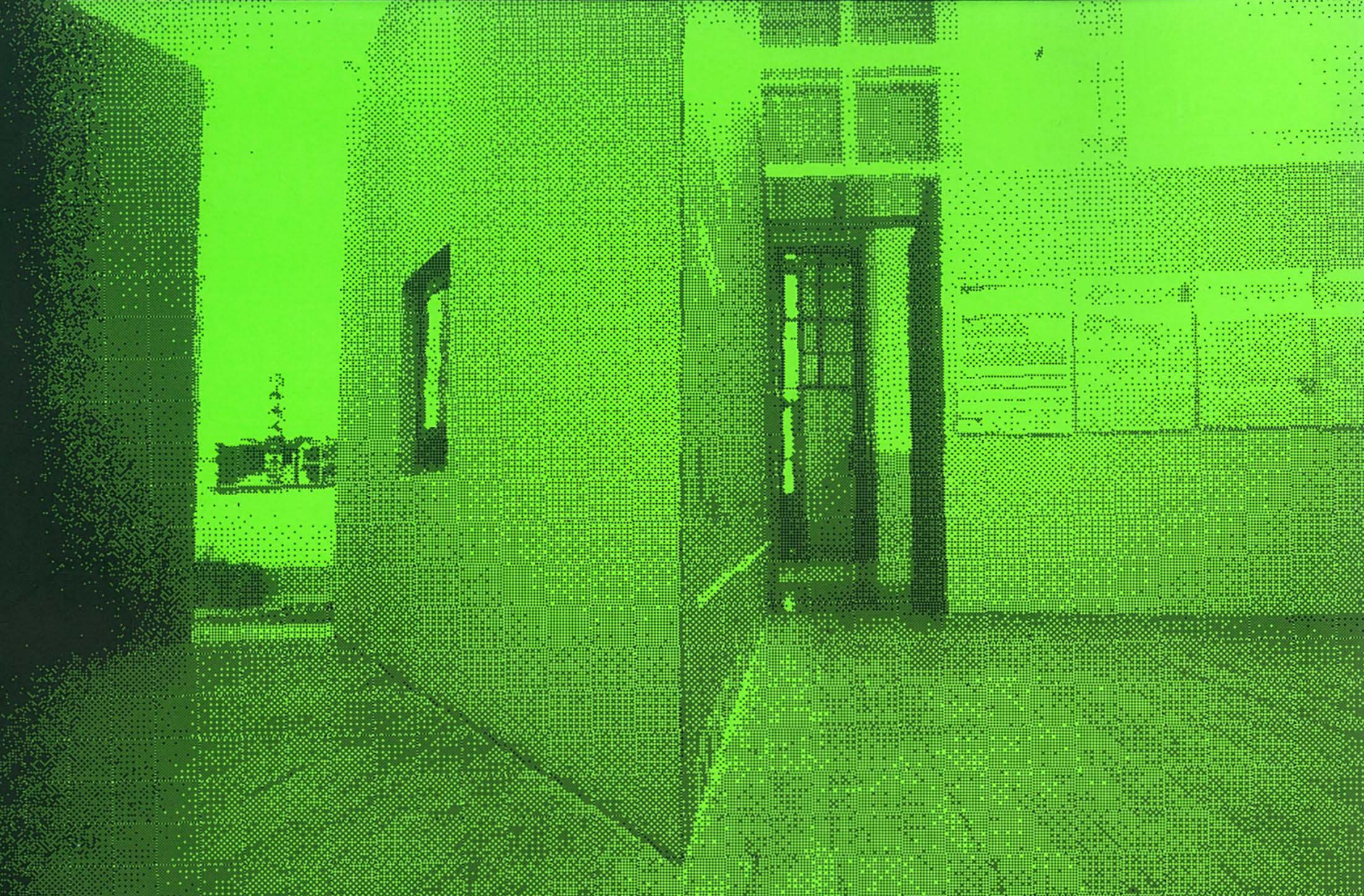

\section{ecdj 2}

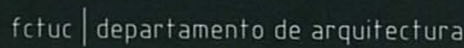

10 anos de arquitectura no colégiodas artes

construir uma escola

tape

encontros de tomar 4

alexandre alves costa vs gonçalo byrne

paulo mendes da rocha 


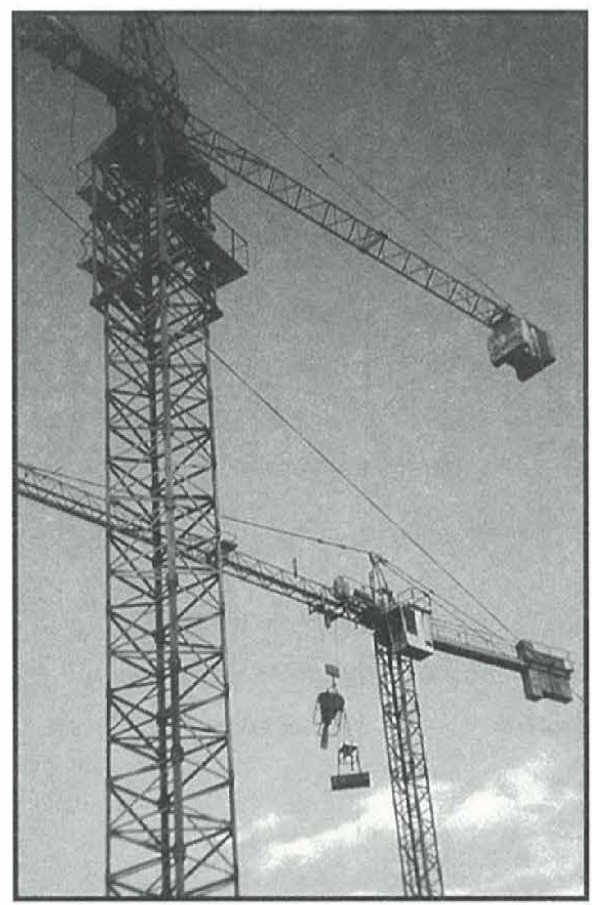

[2 ${ }^{a}$ Reflexão sobre o perfil do curso e o papel da Teoria da Arquitectura] antónio reis cabrita 


\section{> Introdução}

> A primeira reflexão pública que fiz sobre o perfil do curso e o papel da cadeira de Teoria da Arquitectura foi no $1 \%$ Encontro de Tomar. Naquele texto tomei como referência ou objectivo para a formação de um licenciado no curso de Coimbra estar o curso preparado para contribuir para a transformação positiva do quadro físico do habitat urbano (hoje talvez acrescentasse a palavra territorial).

> Para um curso de arquitectura, e não só mas é o que aqui nos reúne, é importante definir um objectivo claro em termos de conteúdo e uma exigência de qualidade senão mesmo de excelência. Num cenário de cerca de 20 cursos e na eventualidade de surgirem mais, mesmo no sector público, haverá certamente um refluxo pelo que o curso de Coimbra deve garantir e intensificar a procura de uma posição de destaque. Evolução, exigência, crítica, adaptação, são as obrigações que nos movem e nos trazem aqui. Esta preocupação deve ser promovida a favor da arquitectura portuguesa em geral, portanto procurando para 0 curso uma relevância a nível nacional e pela melhoria do habitat urbano e territorial a nível regional, que bem precisa.

\section{O nível geral}

> Esta perspectiva de formar licenciados para as transformações positivas acima referidas, é bem intencionada mas vaga e vai ficar vaga, contudo corresponde a um largo conjunto de objectivos formulados nos encontros anteriores e nas responsabilidades e desígnios individuais da equipe de professores que não poderei aqui explanar.

> Pretendo apenas referir que deve ser objectivo levar o conjunto mais alargado possívelde alunos a um nível elevado de exigência relativamente à sua habilitação para aquelas 'transformações positivas'. A matéria prima 'passe a palavra' é, em gera,l intelectualmente e animicamente bem formada, coloco contudo entre parêntesis o grau da sua vocação para o pleno exercício disciplinar onde entram outras dimensões pessoais. Quero com isto dizer 
que aquele desígnio é bem possível. Assim, não é recomendável uma postura elitista através de uma formação de excelência que deixaria muitos para trás nem uma medida populista de nivelar por baixo. Defendo uma postura de treinamento intensivo, exigente e coordenado que estimule a formação e a aprendizagem até limites que deverão ser impulsionados até um nível elevado embora com diálogo e razoabilidade. Refiro apenas o desempenho académico formal, mas devo acrescentar que seria bom poder ceder neste desempenho em troca de uma verdadeira e garantida participação cultural e cívica dos futuros arquitectos em actividades circum-escolares, certamente que a sua intervenção disciplinar seria, mais tarde, bem mais fortificante e transformadora. A propósito deste apelo cultural quero, no entanto referir, usando uma linguagem codificada mas que espero entendivel, que é preciso que os futuros arquitectos percebam a realidade onde vão intervir e venham agarrar essa realidade 'cá em baixo' onde ela está, sabendo que têm depois de subir a escada da qualidade arquitectónica em direcção aos seus legítimos ideais sem a deixar para trás.

\section{O tipo de licenciados}

- O mundo que se avizinha é já muito definivel e é para ele que temos de preparar os alunos, não para servir docilmente esse mundo mas para ter nele uma postura crítica, interventiva e responsável. É bem possível que ao arquitecto venha a ser atribuída por lei a arquitectura e que assim desapareça o conhecido diploma 73/73, mas outros desafios vão surgir. A manter-se o ritmo actual vão surgir anualmente muito mais que os cerca de 450 licenciados actuais fazendo duplicar em dez anos os 8100 membros da Ordem dos Arquitectos e que dispõem de título de arquitecto. Estes números que nos colocarão a breve prazo no topo da União Europeia no índice de arquitectos por 1000 habitantes, exigem algumas reflexões porque se verificará:

um natural refluxo na elevada acorrência aos cursos e que hoje ainda se verifica; uma maior pressão para que os arquitectos ocupem lugares que the são naturalmente atribuiveis nos postos públicos e privados onde se processa a transformação do habitat em geral;

uma maior intervenção do arquitecto em outras áreas afins ou compativeis com a sua formação (e mesmo em outras nada afins);

finalmente, uma forte competição e proletarização ao nivel do papel do arquitecto, fundamentalmente na produção da arquitectura com relevo para o projecto.

> Para enfrentar este desafio numa perspectiva de exigência e qualidade há duas estratégias gerais fundamentais de qualidade ou excelência na formação do arquitecto (não estou a falar de perfis especiais para explorar nichos de mercado conjunturais): a da excelência na aptidão para a produção da arquitectura; a da qualidade num leque de aptidões ao serviço de uma perspectiva diversificada de possibilidades de intervenção cultural no espaço e nos seus elementos constituintes. Qualquer delas leva longo tempo a construir-se. 
> O processo evolutivo do curso de Coimbra leva a concluir estar apostado na primeira estratégia, a da produção da arquitectura, e que se está construindo mais claramente essa linha de há cinco anos para cá. É a linha que se adequa a um curso de dimensão média (40 a 50 alunos ano), enquanto que a segunda estratégia está mais vocacionada para um curso de dimensão maior onde a escala permite instalar um sistema de formação de perfis variados na referida intervenção cultural no espaço. A segunda estratégia em Coimbra, colocando entre parêntesis a falta de dimensão, implicaria um entrosamento elevado com a Faculdade a que o curso pertence e também, ou mais ainda com a própria Universidade, propostas que a experiência revelou serem de muito difícil execução por razões essencialmente institucionais mais do que pessoais.

> Portanto o curso está ou deve estar orientado para uma formação que habilite os licenciados para uma transformação positiva do quadro físico do habitat urbano e territorial numa perspectiva de exigência geral significativamente acentuada, não elitista e concentrada num perfil único que é o da produção da arquitectura.

\section{O amplo leque temático e disciplinar da produção arquitectónica}

Neste quadro da produção da arquitectura há ainda uma vasta latitude temática a contemplar, para além das diversas exigências atribuíveis apenas ao papel central que é o do Projecto como se verá adiante.

> Esta ampla latitude é permitida pelo desempenho de múltiplas tarefas possíveis no campo do Urbanismo com relevo para o planeamento físico de pormenor e o desenho urbano, no campo do Projecto com um leque que vai desde o projecto de ambientes interiores ao projecto do espaço público com todos os escalões intermédios com destaque para o edifício, no campo da avaliação/licenciamento, nomeadamente na apreciação de projectos que impliquem saberes de 'saber fazer' e no campo do ensino da arquitectura, nomeadamente envolvendo estes dois últimos perfis disciplinares, o projecto e a avaliação crítica. Este vasto leque disciplinar amplia-se ainda quando se vislumbra para o futuro não só o perfil tradicional da arquitectura da nova edificação e do urbanismo da expansão urbana, mas também o incremento do perfil já significativo da reabilitação urbana incluindo a da edificação e ainda a conservação do património arquitectónico classificado e as técnicas do seu restauro. Para completar este quadro da formação na produção arquitectónica faz-se ainda uma referência à construção e ao ambiente que já estava incluído mas podia ficar despercebido nas referências acima. A qualidade arquitectónica é a qualidade da ideia acertada com o sítio, o tema e o tempo, mas esta qualidade está cada vez mais fragilizada pela dependência da qualidade da sua materialização que inclui a vertente económica no seu sentido mais amplo e a qualidade ambiental também no seu sentido mais amplo de satisfação dos seus utentes individuais e sociais, directos e indirectos, no início do uso e num certo decurso temporal. Por isso incluo na referida primeira estratégia, a da 'excelência da produção arquitectónica', a necessidade de uma sólida formação em construção e ambiente este entendido em sentido amplo. Admito ainda 
que esta formação tenha um nível mínimo de exigência que permita ainda uma certa autonomia disciplinar de um perfil profissional de arquitectura funcionando mais a montante do processo de projecto portanto essencialmente ao nível programático e da concepção estratégica e de um perfil profissional mais a jusante deste processo ao nível da concepção táctica e da realização produtiva. ${ }^{(1)}$

\section{A linha resultante}

> Esta orientação geral para uma formação no sentido da produção arquitectónica de qualidade exigente e abrangente, relativamente à generalidade dos alunos, não deverá ser monolítica e rígida. Deve satisfazer e aproveitar conjunturas especiais, particularidades pessoais de professores e alunos e particularidades circunstanciais, podendo em função disso ter desvios no sentido de uma formação visando um arquitecto mais conceptualizador culto da forma ou um arquitecto que seja essencialmente um projectista eficaz, sem que isso desvirtue a linha geral da Escola antes a enriqueça. ${ }^{(2)}$

> Isto também significa que a combinação das duas linhas de formação, sem excessos num sentido ou no outro, é afinal a linha resultante correcta para a referida orientação geral de formação no sentido da produção arquitectónica de qualidade exigente e abrangente.

> Apresento então um conjunto de objectivos e conteúdos que apoiam cada uma destas linhas:

a) Apoiando a linha da conceptualização culta da forma sublinham-se as seguintes frentes pedagógicas e capacidades pessoais:

- Sólida preparação em matérias teóricas da generalidade das disciplinas interessando à arquitectura e na Teoria da arquitectura.

- Ampla formação histórica (história das civilizações, da arte, das ideias, da cidade).

- Formação nas Ciências da Ecologia Social (no essencial de cada uma delas mas com particular relevo para a antropologia do espaço).

- Formação cultural (em sentido amplo e com extensões circunescolares)

- Capacidades: de abstracção, de imaginação culturalmente apoiada, de sentido estético nas artes visuais e do espaço.

b) Apoiando a linha da elaboração eficaz do Projecto sublinham-se as seguintes frentes pedagógicas e capacidades pessoais:

- Preparação técnica, básica, estratégica e alargada.

- Sólida formação em construção (em sentido amplo incluindo também a economia, esta igualmente em sentido amplo);

- Formação nas Ciências da Ecologia Social (no essencial de cada uma mas com particular relevo para a sociologia urbana e analítica).

- Capacidades: de síntese, técnico-científica, sentido estratégico, cooperação.

c) Apoiando capacidades comuns: 
- Informação (saber informar-se no futuro).

- Atenção ao contexto e sua percepção, com relevo para a geografia.

- Capacidades: domínio da linguagem arquitectónica pelo desenho, capacidade para adquirir novos conhecimentos, de crítica e auto-crítica.

\section{Papel da Teoria da Arquitectura}

> Tendo sido defendido nos debates anteriores que o Projecto deverá ter uma função central, esta concepção adequa-se ao perfil de formação definida tendo em vista a 'produção arquitectónica exigente e abrangente'. A esta intenção corresponde à colocação do Projecto num papel de coluna vertebral ou tronco alimentado pelas outras disciplinas.

> O Projecto tem duas faces uma preliminar mais virada para a informação fundamental e organizada da intervenção arquitectónica e outra para a conceptualização arquitectónica e seu desenvolvimento coerente a partir da informação de apoio dada como adquirida. Creio que a linha geral seguida em Projecto é uma combinação das duas faces mas com muito mais peso para a segunda. $O$ que me parece bem. É neste sentido que figura um papel para a Teoria para além da leccionação das sua matérias específicas.

> Acontece que o Projecto tem um currículo sequencial de conteúdos em que os exercícios vão mudando do $1^{\circ}$ exercício do $1^{\circ}$ ano até ao último do $5^{\circ}$ ano, portanto não há repetição projectual e a dimensão exercitável é reduzida face à experimental. Pode portanto dizer-se que a teoria de apoio mais directo ao Projecto, ou seja à referida $1^{\text {at }}$ face, só é possível com um acompanhamento próximo, do $1^{2}$ ao último ano e, por isso, é mais recomendável num horizontede médio prazo, que este apoio de teoria ainda que com apoio da História e Construção deveria ser resolvido, pelo menos com uma dimensão mínima indispensável, no âmbito dopróprio Projecto o que não elimina participações pontuais de outros professores que não os de Projecto.

> Uma outra função da Teoria seria a do apoio à integração ou 'digestão' de diversas disciplinas mais humanistas ou mais técnicas para o seu papel na produção arquitectónica, completando a tradução que já terá sido eventualmente iniciada no âmbito de cada cadeira. Seria portanto algo que combinasse traduçãopara o projecto com integração no projecto $e$ de umas traduções e integrações com as outras.

> Pode aqui vislumbrar-se uma outra justificação para o acompanhamento do Projecto pela Teoria, mas agora com a Teoria já mais afastada do Projecto em comparação com o papel que antes se afirmou, atitude que daria conteúdo a uma dimensão Teórico-Práctica da Teoria. Seria uma 'canalização' horizontal de tratamento da informação para os interesses do projecto e para a formação do futuro projectista do $1^{\circ}$ ao $4^{\circ}$ ano, elegendo algumas matérias fundamentais em cada ano a seguir ilustradas com o presente currículo escolar.

$>1^{\circ}$ ano: o espaço físico e sensível (geometria/geografia)

$>2^{\circ}$ ano: o espaço percebido e entendível (antropologia / desenho) 
$>3^{\circ}$ ano: 0 espaço construído e contextualizado, com temas de Teoria / sobre a estrutura conceptual da construção e o papel dos materiais (construções / DAC da edificação)

> $4^{\circ}$ ano: o espaço socializado e a relação espaço urbano público versus espaço privado (urbanologia /I construção II).

> Finalmente, uma referência do que se tem feito e propõe como linha de orientação para o que se deve continuar a fazer em termos de objectivos e conteúdos gerais da Teoria da Arquitectura como disciplina autónoma e no pressuposto de que o desenvolvimento da História no curso inclui a resolução da História das Ideias ou a relação entre as ideiasteóricas e o seu tempo.

> Listam-se portanto cinco vectores ou grandes objectivos que depois são traduzidos concretamente em temas de estudos concretos que deveriam ser permanentemente reformulados e melhorados, o que infelizmente e por minha culpa não tem sido feito.

1O Objectivo: Definição da estrutura conceptual ou dos conceitos ligados ao exercício arquitectónico:

- conceitos disciplinares isolados: a Matéria; a Forma; o Espaço;

- conceitos disciplinares articulados: matérialformalespaço;

- conceitos interdisciplinares ou de ligação: matéria/custo;

- conceitos transdisciplinares ou transversais: impacto ambiental;

2- Objectivo: Percepção da complexidade integrada, dinâmica e contraditória do contexto nas suas vertentes social, cultural, técnica e administrativa:

- os agentes / instituições e seus papeis;

- as dinâmicas sociais;

- as mutações culturais (rural, urbana, periferia, centralidade, etc.);

- as profissões liberais, o papel do arquitecto;

- a gestão social da ocupação do espaço;

3o Objectivo: Entendimento do confronto de ideias num espaço mundial / regional aberto e livre e seu impacto na arquitectura:

- pluralidade cultural válida co-existente no tempo e no espaço (por exemplo o urbano, o novo rural, a nova periferia urbana);

- contradições entre valores todos eles aspirados (exemplo proximidade e isolamento, naturalidade $e$ artificialidade, etc.);

- responsabilidade (a noção de crítica e autocrítica; a capacidade de síntese e decisão sem excluir as parcerias profissionais e sociais); 
4 Objectivo: $O$ carácter instrumental da Teoria. Compreensão do processo de Projecto:

- O programático. Os programas e o contexto. O cliente. A administração urbanística. A habitação;

- O conceptual. O método e os critérios de apoio à concepção. O que é o desenho no projecto, no desenho urbano, e no ordenamento físico;

- O compositivo. Os instrumentos da composição clássicalclassicizante. Os instrumentos da composição romântica (ainda não executado).;

- O de avaliação e crítica É mínimo e feito somente no tema habitação. Agora a nível empírico relativamente à cidade próxima ou área urbana.

5 Objectivo: Relação do arquitecto com a cidade:.

- Toda a arquitectura é uma arquitectura urbana;

- Todo o arquitecto é um agente urbano activo e responsável;

- O arquitecto participa no urbanismo, desenha arquitectura urbana e projecta o espaço público; 